\title{
PENDIDIKAN AGAMA ISLAM (PAI) DALAM PENANGGULANGAN RADIKALISME
}

Ulfa

Institut Agama Islam Sunan Giri Bojonegoro

Email: ulfamasyhur8@gmail.com

\begin{abstract}
Indonesia is a plural and heterogeneous country, and has the potential for multi-ethnic, cultural, multi-religious wealth, all of which are the potential to build a large multicultural country, any religion has a tendency to carry out truth claims because religion is a belief value that must be held firmly by its adherents, the attitude of the truth claim will be positive if it is only intrinsic Orientation in its appreciation and application, not for extrinsic orientation that causes negative prejudice and conflict. Intrinsic religion fulfills all life with motivation and meaning, while extrinsic religion makes religion enslaved to support and justify personal interests, The aim of Islamic education is to form perfect human being.. then Islamic religious education is the solution to make followers of religion not included in the radical, by giving Learning and methods of Non-Radicalism Islamic Education.
\end{abstract}

Keywords: Indonesia, Plural, Islamic, Education, Radicalism.

\section{PENDAHULUAN}

Negara Indonesia merupakan Negara plural dan heterogen, dan memiliki potensi kekayaan multietnis, mutikultural, multiagama yang kesemuanya merupakan potensi untuk membangun negara multikultural yang besar. Indonesia terdiri atas sejumlah besar kelompok-kelompok etnis, budaya, agama, dan lain-lain yang masing-masing plural (jamak) dan sekaligus juga heterogen. ${ }^{1}$

Pada dasarnya agama apapun memiliki kecenderungan untuk melakukan truth claim (mengkalim sebagai yang paling benar) karena agama merupakan nilai kepercayaan yang harus dipegang teguh oleh pemeluknya, sikap truth claim tersebaut akan bernilai positif apabila hanya dioreintasikan ke dalam (intrinsic Orientation) dalam penghayatan dan aplikasinya, bukan untuk keluar dirinya (ekstrinsic orientation) yang menyebabkan prasangka negative dan konflik.Agama Intrinsik memenuhi seluruh hidup dengan motivasi

\footnotetext{
${ }^{1}$ B.Kusumohamidjojo, Kebinekaan Masyarakat Indonesia; Suatu Problematik Filsafat Kebudayaan, (Jakarta; Grasindo, 2000), hlm. 45
} 
dan makna, sedang agama ektrinsik menjadikan agama diperbudak untuk mendukung dan membenarkan kepentingan pribadi. ${ }^{2}$

Apabila praktik agama mengarah pada truth claim yang mengasingkan terhadap kebenaran lainnya, maka sikap yang demikian dalam pandangan Kimball, sama halnya dengan melakukan pembusukan terhadap agama. ${ }^{3}$

Tujuan pendidikan Islam adalah untuk membentuk manusia paripurna (insan kamil), tujuan tersebut merupakan tujuan tertinggi dari pendidikan Islam sebab sesuai dengan tujuan hidup manusia, dan peranannya sebagai makhluk ciptaan Allah.Indikator dari insan kamil adalah pertama: Menjadi hamba Allah,kedua: mengantarkan subjek didik menjadi khalifah Allah fi al-ardh, dan yang ketiga adalah untuk memperoleh kesejahteraaan dan kebahagiaan di dunia dan akhirat, baik individu maupun masyarakat. ${ }^{4}$

Namun tujuan mulia tersebut akan terasa sulit untuk bisa dicapai sepanjang hayat manusia, apabila dicemari oleh pemikiran, wacana, dan gagasan-gagasan yang menyesatkan. Maka pembelajara Pendidikan Agama Islam baik dalam pendidikan Formal dan non formal hendaknya dapat menjawab tantangan tersebut. Dan memang Pendidikan Islam sendiri telah eksis dan memiliki karakteristik yang khas, khususnya dalam diskursus pendidikan di Indonesia. ${ }^{5}$

\section{PEMBAHASAN}

\section{Pendidikan Agama Islam}

Bicara tentang pengertian Pendidikan Agama Islam pada umumnya mengacu kepada term al-Tarbīyah, al-Ta'dīb, dan al-Ta'līm. Dari ketiga istilah tersebut term yang popular digunakan dalam praktik Pendidikan Islam ialah term al-Tarbīyah, sedangkan term al-Ta'dīb dan al-Ta'līm jarang sekali digunakan.

Terlepas dari perbedaan penggunaan term yang tiga ini (al-Tarbīyah, alTa'dīb, dan al-Ta'līm), makna dari ketiga term di atas, secara terminologi, para ahli

\footnotetext{
${ }^{2}$ Moh.Roqib, Ilmu Pendidikan Islam Pengembangan pendidikan Integratif di Sekolah Keluarga dan Masyarakat, (Yogyakarta;LKis, 2009), hlm. 189

${ }^{3}$ Syamsul arifin, Studi Islam Kontemporer; Arus Radikalisme dan Multikulturalisme di Indonesia (Malang: Intrans Publising, 2015) hlm. 10

${ }^{4}$ Prof. Dr. H. Ramayulis. Ilmu Pendidikan Islam, (Jakarta, Kalam Mulia, 2011) Cet. IX, hlm. 134-136.

${ }^{5}$ Ngainun Naim. Pendidikan Multikultural, Konsep dan Aplikasi ( Yogyakarta: Ar-Ruzz Media Group, 2008), hlm.51
} 
Pendidikan Islam telah mencoba menformulasikan pengertian Pendidikan Islam. Di antara batasan yang sangat variatif tersebut adalah:

a. Zakiah Darajat menjelaskan pendidikan Agama Islam adalah usaha berupa bimbingan dan asuhan terhadap anak didik agar kelak setelah selesai pendidikannya dapat memahami dan mengamalkan ajaran Agama Islam serta menjadikannya sebagai pandangan hidup (way of life). Yang dilaksanakan berdasarkan ajaran Agama Islam. Serta menjadikan ajaran Agama Islam itu sebagai suatu pandangan hidupnya demi keselamatan hidup di dunia maupun di akhirat kelak. ${ }^{6}$

b. Ahmad Tafsir mendefinisikan Pendidikan Islam sebagai bimbingan yang diberikan oleh seseorang kepada seseorang agar ia berkembang secara maksimal sesuai dengan ajaran Islam. Bila disingkat, Pendidikan Islam ialah bimbingan terhadap seseorang agar ia menjadi Muslim semaksimal mungkin. ${ }^{7}$

c. Achmadi memberikan penjelasan bahwa yang dimaksud dengan Pendidikan Islam adalah segala usaha untuk memelihara dan mengembangkan fitrah manusia serta sumber daya manusia yang ada padanya menuju terbentuknya manusia seutuhnya (insān kamīl ) sesuai dengan norma Islam. ${ }^{8}$

d. Zuhairini, Pendidikan Agama Islam adalah usaha sadar, yakni kegiatane. Zuhairini, Pendidikan Agama Islam adalah usaha sadar, yakni kegiatan bimbingan ke arah pembentukan kepribadian peserta didik secara sistematis dan pragmatis, supaya sesuai dengan ajaran Islam, sehingga terjadinya

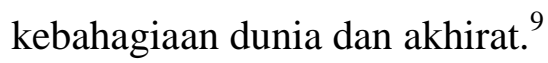

Jelaslah bahwa proses kependidikan merupakan rangkaian usaha membimbing, mengarahkan potensi hidup manusia yang berupa kemampuan belajar, sehingga terjadilah perubahan di dalam kehidupan pribadinya sebagai makhluk individu dan sosial serta dalam hubungannya dengan alam sekitar dimana ia hidup. Proses tersebut senantiasa berada dalam nilai-niolai Islami, yaitu nilainilai yang melahirkan norma-norma syariah dan akhlak al-karimah. ${ }^{10}$

\footnotetext{
${ }^{6}$ Zakiah Darajat, Metodik Khusus Pengajaran Agama Islam (Jakarta: Bumi Aksara, 1995 ), hlm. 50.

${ }^{7}$ Ahmad Tafsir, Ilmu Pendidikan dalam Perspektif Islam (Bandung: Remaja Rosdakarya, 1992), hlm. 32.

${ }^{88}$ Achmadi, Ideologi Pendidikan Islam Paradigma HumanismeTeosentris (Yogyakarta: PustakaPelajar, 2005), hlm. 31.

${ }^{9}$ Zakiah Darajat, Pendidikan Agama Islam ( Solo: Ramadhani, 1993), hlm. 11.

${ }^{10}$ Muzayyin Arifin, Filsafat Pendidikan Islam (Jakarta: Bumi Aksara, 2014), hlm.15
} 
Pendidikan Agama Islam adalah upaya sadar dan terencana dalam menyiapkan peserta didik untuk mengenal, memahami, menghayati, hingga mengimani ajaran Agama Islam dibarengi dengan tuntunan untuk menghormati penganut agama lain dalam hubungannya dengan kerukunan antarumat beragama hingga terwujud kesatuan persatuan bangsa. Pendapat Zakiyah Darajat seperti yang dikutip oleh Abdul Majid dan Dian Andayani menyatakan bahwa Pendidikan Agama Islam adalah suatu usaha untuk membina dan mengasuh peserta didik agar senantiasa dapat memahami ajaran Islam secara menyeluruh. Lalu menghayati tujuan, yang pada akhirnya dapat mengamalkan serta menjadikan Islam sebagai pandangan hidup. ${ }^{11}$

Fungsi utama pendidikan yaitu untuk menumbuhkan kreativitas peserta didik dan menanamkan nilai yang baik. ${ }^{12}$ Sedangkan fungsi Pendidikan Agama Islam yaitu:

a. Pengembangan: untuk meningkatkan keimanan dan ketakwaan peserta didik kepada allah SWT yang telah ditanamkan dalam lingkungan keluarga.

b. Penanaman nilai sebagai pedoman hidup untuk mencari kebahagiaan hidup di dunia dan akhirat.

c. Penyesuaian mental untuk menyesuaikan diri dengan lingkungannya baik lingkungan fisik maupun lingkungan sosial dan dapat mengubah lingkungannya sesuai dengan ajaran agama Islam.

d. Perbaikan yaitu untuk memperbaiki kesalahan-kesalahan, kekurangan, dan kelemahan peserta didik dalam keyakinan, pemahaman, dan pengalaman ajaran dalam kehidupan sehari hari.

e. Pencegahan yaitu untuk menangkal hal-hal negatif dari lingkungannya atau dari budaya lain yang dapat membahayakan dirinya dan menghambat perkembagannya menuju manusia indonesia seutuhnya.

f. Pengajaran tentang ilmu pengetahuan keagamaan secara umum (alam nyata dan nir-nyata), sistem dan fungsionalnya.

\footnotetext{
${ }^{11}$ Abdul Madjid dan Dian Andayani, Pendidikan Agama Islam Berbasis Kompetensi Konsep dan Implementa si Kurikulum 2004, (Bandung: PT Remaja Rosdakarya, 2004), Cet. 1, hlm. 130.

${ }^{12}$ Chabib Thoha, Kapita Selekta Pendidikan Islam, (Yogyakarta: Pustaka Pelajar, 1996), Cet. 1, hlm. 59 .
} 
g. Penyaluran, yaitu untuk menyalurkan anak-anak yang memiliki bakat khusus di bidang agama Islam agar dapat berkembang secara optimal sehingga dapat dimanfaatkan untuk dirinya sendiri dan bagi orang lain. $^{13}$

Dapat disimpulkan tujuan Pendidikan Agama Islam yaitu untuk meningkatkan keimanan, pemahaman, penghayatan, dan pengamalan peserta didik tentang Agama Islam sehingga menjadi manusia muslim yang beriman dan bertakwa kepada Allah serta berakhlak mulia dalam kehidupan pribadi, bermasyarakat, berbangsa dan bernegara. ${ }^{14}$ Menurut M. Athiyah Al-Abrasyi sebagaimana dikutip oleh Zuhairini, menerangkan bahwa tujuan pendidikan Agama Islam secara umum adalah: ${ }^{15}$

a. Untuk membantu pembentukan akhlak yang mulia.

b. Persiapan untuk kehidupan dunia dan kehidupan akhirat.

c. Persiapan untuk mencari rejeki dan pemeliharaan segi kemanfaatan.

d. Menumbuhkan semangat ilmiah pada pelajar dan memuaskan keinginan tahu untuk mengetahui dan memungkinkan ia mengkaji ilmu demi ilmu itu sendiri.

e. Menyiapkan pelajar dari segi profesional, tehnis, supaya dapat menguasai profesi tertentu, dan keterampilan tertentu agar ia dapat mencari rezeki dalam hidup di samping memelihara segi kerohanian.

\section{Radikalisme.}

Radikal berasal dari kata radic yang berarti akar, dan radikal adalah (sesuatu) yang bersifat mendasar atau hingga akar-akarnya. Predikat ini bisa dikenakan pada pemikiran atau paham tertentu.sehingga muncul istilah pemikiran yang radikal dan bisa pula gerakan. Berdasarkan hal itu, radikalisme diartikan dengan paham atau aliran

\footnotetext{
${ }^{13}$ Abdul Madjid dan Dian Andayani, Pendidikan Agama Islam Berbasis Kompetensi Konsep dan Implementa si Kurikulum 2004, hlm. 134-135

${ }^{14}$ Muhaimin, dkk., Paradigma Pendidikan Islam Upaya Mengefektifkan Pendidikan Agama Islam di Sekolah, (Bandung: Remaja Rosdakarya, 2001), Cet. 1, hlm. 75.

${ }^{15}$ Zuhairini, dkk., Metodologi Pendidikan Agama, (Solo: Ramadhani, 1993), Cet.I, hlm. 17
} 
keras yang menginginkan perubahan atau pembaruan sosial dan politik dengan cara keras atau drastic dan sikap ekstrem suatu aliran politik. ${ }^{16}$

Yusuf al-Qardhawi memberikan istilah radikalisme dengan istilah al-Tatarruf ad-Din. Atau bahasa lugasnya adalah untuk mempraktekkan ajaran agama tidak semestinya, atau mempraktekkan ajaran agama dengan mengambil posisi Tarf atau pinggir. Jadi jauh dari substansi ajaran agama Islam. Yaitu ajaran moderat di tengahtengah. Biasanya posisi pinggir ini adalah sisi yang berat atau memberatkan dan berlebihan, yang tidak sewajarnya. Apa makna dari implikasi cara beragama seperti ini, ialah bahwa dalam praktek pengalaman beragama terdapat orang-orang berperilaku ekstrim, sehingga melebihi keawajaran yang semestinya. ${ }^{17}$

Radikalisme dapat dibedakan ke dalam dua level, yaitu level pemikiran dan level tindakan atau aksi. Pada level pemikiran, radikalisme masih berupa wacana konsep dan gagasan yang masih diperbincangkan, yang intinya mendukung penggunaan cara-cara kekerasan untuk mencapai tujuan. Adapun pada level aksi atau tindakan, radikalisme bisa berada pada ranah sosial, politik dan agama. Pada ranah politik faham ini Nampak tercermin dari adanya tindakan memaksakan pendapatnya dengan cara-cara yang inskontitusional, bahkan bisa berupa tindakan mobilisasi masa untuk kepentingan politik tertentu dan berujung pada konflik sosial. ${ }^{18}$

Ketika agama telah memasuki ranah ideologi, maka ketika itu agama telah menjadi bagian dari kebenaran yang harus dipertahankan dan diperjuangkan dengan berbagai cara termasuk cara-cara yang hakikatnya melawan teks agama itu sendiri. Perusakan, pembakaran, penghancuran, dan pengeboman atas nama agama yang dilakukan dengan mengucapkan Takbir (Allahu Akbar) adalah sekelumit kisah tentang wajah agama dengan tafsir agama yang keras, radikal atau fundamental. ${ }^{19}$

\footnotetext{
${ }^{16}$ Imam Tayibi, dkk, "Radikalisme Agama Sebagai Salah Satu Bentuk Perilaku Menyimpang” Jurnal Kriminologi Indonesia, Vol.3 No.1 (Juni:2003), hlm.45

${ }^{17}$ Anzar Abdullah, "Gerakan Radikalisme dalam Islam Perspektif Historis", Jurnal ADDIN, Vol.10.No.1 (Februari, 2016), hlm.5

${ }^{18}$ Abdul Munip, "Menangkal Radikalisme Agama di Sekolah”, Jurnal Pendidikan Islam, Vol.1 No. 2 (Desember 2012), hlm. 162

${ }^{19}$ Nur Syam, Tantangan Multiklturalisme Indonesia dari Radikalisme Menuju Kebangsaan, (Yogyakarta: Kansius, 2009), hlm. 132
} 


\section{Pendidikan Agama Islam (PAI) dan Penanggulangan Radikalisme}

Penyelenggaraan pendidikan di Indonesia menurut UU Nomor 20 Tahun 2003 pasal 1 ayat (2) disebutkan bahwa suatu Pendidikan Nasional adalah pendidikan yang berdasarkan Pancasila dan Undang-Undang Dasar 1945 yang berakar pada nilai-nilai agama, kebudayaan nasional Indonesia dan tanggap terhadap tuntutan perubahan zaman $^{20}$. Tidak bisa dipungkiri bahwa pendidikan Islam, baik sebagai system maupun insitusinya, merupakan warisan budaya bangsa, yang berurat berakar pada masyarakat bangsa Indonesia. Dengan demikian jelas bahwa pendidikan Islam akan merupakan bagian integral dari system pendidikan nasional.

Kebutuhan akan pendidikan merupakan hal yang tidak bisa dipungkiri, bahkan semua itu merupakan hak semua warga Negara, berkenaan dengan ini, di dalam UUD’45 Pasal 31 ayat (1) secara tegas disebutkan bawha; “Tiap-tiap warga Negara berhak mendapat pengajaran". Tujuan pendidikan nasional dinyatakan dalam UU RI No. 20 Tahun 2003 Pasal 3 bertujuan untuk berkembangnya potensi peserta didik agar menjadi manusia yang beriman dan bertaqwa kepada Tuhan Yang Maha Esa, berakhlak mulia, sehat, berilmu, cakap, kreatif mandiri, dan menjadi warga Negara yang demokratis serta bertanggung jawab.

Tujuan pendidikan nasional suatu bangsa menggambarkan manusia yang baik menurut pandangan hidup yang dianut oleh bangsa itu, dan tujuan pendidikan sesuatu bangsa mungkin tidak akan sama dengan bangsa lainnya, karena pandangan hidup mereka biasanya tidak akan sama ${ }^{21}$. Tetapi pada dasarnya pendidikan setiap bangsa tentu sama, yaitu semua menginginkan terwujudnya manusia yang baik yaitu manusia yang sehat, kuat serta mempunyai ketrampilan, pikirannya cerdas serta pandai, dan hatinya berkembang dengan sempurna.

Pendidikan pada dasarnya suatu upaya terus menerus yang bertujuan mengembangkan seluruh potensi kemanusiaan peserta didik dalam mempersiapkan mereka agar mampu menghadapi menghadapi berbagai tantangan dalam kehidupannya. Dengan demikian, di satu sisi pendidikan merupakan sebuah upaya penanaman nilai-nilai kepada peserta didik dalam rangka membentuk watak dan

\footnotetext{
${ }^{20}$ Hasbullah, Dasar-dasar Ilmu Pendidikan, (Jakarta, PT Raja Grafindo Persada, 2005) Cet ke-4, hlm. 174

${ }^{21}$ Hasbullah, Dasar-dasar Ilmu Pendidikan,... hlm. 310
} 
kepribadiannya. Selanjutnya, pendidikan mendorong peserta didik untuk mewujudkan nilai-nilai tersebut ke dalam perilaku dalam kehidupan sehari-hari ${ }^{22}$.

Sedangkan Pendidikan Agama Islam mempunyai fungsi sebagaimana Menurut Kurshid Ahmad, adalah sebagai berikut:

1) Alat untuk memelihara, memperluas dan menghubungkan tingkat-tingkat kebudayaan, nilai-nilai tradisi dan sosial, serta ide-ide masyarakat dan bangsa.

2) Alat untuk mengadakan perubahan, inovasi dan perkembangan yang secara garis besarnya melalui pengetahuan dan skillyang baru ditemukan, dan melatih tenaga-tenaga manusia yang produktif untuk menemukan perimbangan perubahan sosial dan ekonomi. ${ }^{23}$

Sesuai dengan hakikat Pendidikan Islam yang merupakan suatu proses yang berlangsung secara kontiniu atau berkesinambungan, maka tugas dan fungsi yang diemban oleh Pendidikan Islam adalah pendidikan manusia seutuhnya dan berlangsung sepanjang hayat. Konsep ini bermakna bahwa tugas dan fungsi pendidikan memiliki sasaran pada peserta didik yang senantiasa tumbuh dan berkembang secara dinamis, sejak masih dalam kandungan sampai ajal menjemputnya.Secara umum tugas Pendidikan Islam adalah membimbing dan mengarahkan pertumbuhan dan perkembangan peserta didik dari tahap ke tahap kehidupannya sampai mencapai titik kemampuan yang optimal sesuai dengan tuntutan ajaran Islam. $^{24}$

Kelompok radikalisme menurut Yusuf al Qardhawi memiliki ciri-ciri antara lain:

1) Sering mengklaim kebenaran tunggal dan menyesatkan kelompok lain yang tidak sependapat,

2) Radikalisme mempersulit agama Islam yang sejatinya samhah (ringan) dengan menganggap pekerjaan sunah adalah wajib dan makruh seakan-akan haram.

\footnotetext{
22 Abdui Rahman Shaleh, Pendidikan Agama dan Pembangunan Watak Bangsa, (Jakarta: PT Raja Grafindo Persada, 2006) hlm.259

${ }^{23}$ Dr. Abdul Mujib, M. Ag. Dan Dr. Jusuf Mudzakkir, M. Si. Ilmu Pendidikan Islam.(Jakarta, PrenadaMedia. 2006), hlm.69

${ }^{24}$ 38Al-Rasyidin dkk, Pendekatan Historis, Teoritis dan Praktis Filsafat Pendidikan Islam (Jakarta: Ciputat Press, 2005), hlm. 32.
} 
3) Kelompok radikal kebanyakan berlebihan dalam beragama yang tidak ada tempatnya.

4) Kasar dalam berinteraksi, keras dalam berbicara dan emosional dalam berdakwah

5) Mudah berburuk sangka kepada orang laindi luar golongannya.

6) Mudah mengkafirkan orang lain yang berbeda pendapat. ${ }^{25}$

Penyebab munculnya radikalisme Islam

1) Pemahaman agama yang literal, memahami ayat sepotong-potong

2) Bacaan yang salah terhadap sejarah Islam yang dikombinasikan dengan idealisasi berlebihan terhadap Islam pada masa tertentu.

3) Deprivasi politik, sosial dan ekonomi yang masih bertahan dalam masyarakat.

4) Mudah terpengaruhnya umat Islam terhadap paham baru tanpa diikuti dengan sikap kritis dalam meyakuninya. ${ }^{26}$

\section{Pembelajaran Pendidikan Agama Islam Non Radikalisme}

Misi ajaran Islam yang sebenarnya sangat luhur dan mulia sering kali Mengalami distorsi akibat pemahaman yang keliru terhadap beberapa aspek ajaran Islam yang berpotensi menimbulkan faham radikalisme. Beberapa diantaranya adalah:

1) Penjelasan tentang jihad. Jihad adalah konsep ajaran Islam yang paling sering menimbulkan kontroversi dikalangan umat. Bagi kaum radikalis, jihad selalu bermakna qitâl atau peperangan atau perjuangan dengan mengangkat senjata. Sebenarnya makna jihad mempunyai arti yang beragam meskipun salah satunya perang melawan musuh Islam. Ada beberapa pengertian Jihad:

- Perang

- Haji Mabrur

- Menyampaikan kebenaran kepada penguasa yang dzalim

- Berbakti kepada orang tua

- Menuntut ilmu dan mengembangkan pendidikan

- Membantu fakir dan miskin. ${ }^{27}$

\footnotetext{
${ }^{25}$ Irwan Masduqi, "Deradikalisme Pendidikan Islam Berbasis Khazah Pesantren" Jurnal Pendidikan Islam, Vol.1, No.2, (Desember 2012) hlm.3-4

${ }^{26}$ Abdul Munip, "Menangkal radikalisme Agama di Sekolah" Jurnal Pendidikan Islam, Vol.1, No.2,

(Desember 2012) hlm.163-164
} 
2) Menjelaskan tentang toleransi. Ajaran Islam sebenarnya syarat dengan toleransi. Namun toleransi sering dipahami secara sempit, sehingga tidak mampu menjadi perekat intra dan antar umat beragama.

3) Pengenalan tentang hubungan ajaran Islam dengan kearifan local, Islam yang turun di aran bukanlah Islam uang bebas dari sejarah local yang mengitarinya. Artinya memahami Islam tidak bisa dipisahkan dari akar sosio-historis di mana Islam berada.

\section{Strategi Pembelajaran Pendidikan Agama Islam Non Radikalisme}

\section{1) Strategi Pembelajara Inklusif}

Pendidikan Islam mempunyai peran yang strategis dalam membangun inklusivitas dan sekaligus memberantas eksklusivitas keagamaan di Indonesia.hal ini dikarenakan pendidikan media yang paling efektif dan efisien dalam upaya melakukan penanaman nilai-nilai kemanusiaan dan religious kepada peserta didik pendidikan Islam yang lebih menekankan pada aspek doktriner normative cenderung melahirkan sikap eksklusif-literalis. Sikap eksklusif cenderung berusaha memonopoli kebenaran, tidak mau mendengar dan dan memahami orang lain serta kecenderungan bersikap otoriter. Kecenderungan ini memperlihatkan mudahnya seseorang menghukumi orang lain dengan kejam dan tidak manusiawi hal inilah yang menjadi salah satu fakor awal sikap radikal yang berujung pada aksi terror. ${ }^{28}$ Dalam menghadapi pluralitas masyarakat yang multi etnik dan multi religi dibutuhkan pendidikan Islam yang inklusif yang berorientasi pada kesalehan sosial dengan tidak melupakan kesalehan individual. Inklusif adalah sikap berfikir terbuka dan menghargai perbedaan dalam bentuk pendapat, pemikiran, etnis, tradisi budaya hingga perbedaan agama. ${ }^{29}$

\section{2) Strategi Pembelajaran kontekstual}

Strategi ini strategi pembelajaran yang mengaitkan materi yang diajarkan dengan kehidupan nyata.pembelajaran ini memotivasi peserta didik menghubungkan materi yang diperoleh dengan penerapan dalam kehidupan nyata. Dengan konsep ini

\footnotetext{
${ }^{27}$ Sjuhada Abduh dan Nahar Nahrawi, "Makna Jihad dan Respon Komunitas Muslim Serang Pasca Eksekusi Imam Samudra", Jurnal Harmoni, Vol.VIII, No.32, (Oktomber 2009) hlm.113-130

${ }_{28}^{28}$ Sumartana, Pluralisme Konflik dan Pendidikan Agama di Indonesia (Yoyakarta Interfidei 2001), hlm. 252

${ }^{29}$ Achmad Junaidi, Gus Dur Presiden Kiyai Indonesia; Pemikiran Nyentrik Abdurrahman Wahid dari

Pesantren hingga Parlemen Jalanan (Surabaya: Diantama, 2010) hlm. 25
} 
diharapkan hasil pembelajaran lebih bermakna. Proses pembelajaran berlangsung alamiah dalam bentuk kegiatan peserta didik bekerja dan mengalami, bukan mentransfer pengetahuan dari guru ke peserta didik. ${ }^{30}$

Strategi pembelajaran Kontekstual bersumber dari pendekatan kontruktivis. Menurut teori belajar kontruktivis, bahwa individu belajar dengan cara mengkontrusi makna melalui interaksi dengan lingkungannya kemudian menginterpretasikannya. Pada intinya pembelajaran pendidikan agama Islam secara kontekstual selalu mengkaitkan pembelajaran PAI dengan konteks dan pengalaman-pengalaman hidup peserta didik yang beraneka ragam dan konteks-konteks masalah serta situasi-situari riil kehidupan. ${ }^{31}$

\section{KESIMPULAN}

Dari uraian di atas dapatlah disimpulkan sebagai berikut:

1. Pendidikan Agama Islam adalah upaya sadar dan terencana dalam menyiapkan peserta didik untuk mengenal, memahami, menghayati, hingga mengimani ajaran Agama Islam dibarengi dengan tuntunan untuk menghormati penganut agama lain dalam hubungannya dengan kerukunan antarumat beragama hingga terwujud kesatuan persatuan bangsa.

2. Radikalisme diartikan dengan paham atau aliran keras yang menginginkan perubahan atau pembaruan sosial dan politik dengan cara keras atau drastic dan sikap ekstrem suatu aliran politik.

3. Pendidikan Agama Islam (PAI) dan Penanggulangan Radikalisme, dengan memperhatikan:

- Memberikan Pembelajaran Pendidikan Agama Islam Non Radikalisme, diantaranya adalah:

a) Penjelasan tentang jihad.

b) Menjelaskan tentang toleransi.

c) Pengenalan tentang hubungan ajaran Islam dengan kearifan local,

- Memberikan Strategi Pembelajaran Pendidikan Agama Islam Non Radikalisme, yakni;

\footnotetext{
${ }^{30}$ Khamdan dkk, Strategi Pembelajaran Pendidikan Agama Islam di sekolah; Teori Metodologi dan Implementasi (Yogyakarta;Idea press, 2012), hlm. 182-183

${ }^{31}$ Muhaimin, Rekontruksi Pendidikan Islam, (Jakarta: PT Raja Grafindo Persada, 2009), hlm. 261-262.
} 

a) Strategi Pembelajara Inklusif
b) Strategi Pembelajaran kontekstual

\section{DAFTAR PUSTAKA}

Abduh , Sjuhada dan Nahrawi, Nahar, (2009) "Makna Jihad dan Respon Komunitas Muslim Serang Pasca Eksekusi Imam Samudra”, Jurnal Harmoni, Vol.VIII, No.32, (Oktomber 2009)

Abdullah, Anzar, (2016) “Gerakan Radikalisme dalam Islam Perspektif Historis”, Jurnal ADDIN, Vol.10.No.1 (Februari, 2016),

Achmadi,(2005), Ideologi Pendidikan Islam Paradigma HumanismeTeosentris Yogyakarta: PustakaPelajar,

Ahmad Tafsir, Ahmad, (1992) Ilmu Pendidikan dalam Perspektif Islam Bandung: Remaja Rosdakarya,

Al-Rasyidin dkk, (2005), Pendekatan Historis, Teoritis dan Praktis Filsafat Pendidikan Islam Jakarta: Ciputat Press

Arifin, Muzayyin, (2014) Filsafat Pendidikan Islam, Jakarta: Bumi Aksara, Arifin, Syamsul, (2015). Studi Islam Kontemporer; Arus Radikalisme dan Multikulturalisme di Indonesia Malang: Intrans Publising,

Darajat,Zakiyah,(1993), Pendidikan Agama Islam Solo: Ramadhani, Darajat, Zakiyah (1995) Metodik Khusus Pengajaran Agama Islam Jakarta: Bumi Aksara, Hasbullah, (2005), Dasar-dasar Ilmu Pendidikan, (Jakarta, PT Raja Grafindo Persada, 2005) Cet ke-4,

Junaidi, Achmad, (2010), Gus Dur Presiden Kiyai Indonesia; Pemikiran Nyentrik Abdurrahman Wahid dari Pesantren hingga Parlemen Jalanan, Surabaya: Diantama, Khamdan dkk, (2012), Strategi Pembelajaran Pendidikan Agama Islam di sekolah; Teori Metodologi dan Implementasi Yogyakarta;Idea press, Kusumohamidjojo, (2000), Kebinekaan Masyarakat Indonesia; Suatu Problematik Filsafat Kebudayaan, Jakarta; Grasindo, 
Madjid Abdul dan Andayani, Dian (2004) Pendidikan Agama Islam Berbasis Kompetensi Konsep dan Implementa si Kurikulum 2004, Bandung: PT Remaja Rosdakarya, , Cet. 1

Madjid, Abdul dan Andayani, Dian(2004), Pendidikan Agama Islam Berbasis

Kompetensi Konsep dan Implementa si Kurikulum

Masduqi, Irwan, (2012) "Deradikalisme Pendidikan Islam Berbasis Khazah Pesantren" Jurnal Pendidikan Islam, Vol.1, No.2, (Desember 2012)

Muhaimin, dkk., (2001), Paradigma Pendidikan Islam Upaya Mengefektifkan Pendidikan Agama Islam di Sekolah, Bandung: Remaja Rosdakarya,

Muhaimin, (2009), Rekontruksi Pendidikan Islam, Jakarta: PT Raja Grafindo Persada, Mujib, Abdul, Dan Mudzakkir, Jusuf, (2006), Ilmu Pendidikan Islam. Jakarta, PrenadaMedia.

Munip, Abdul, (2012) "Menangkal Radikalisme Agama di Sekolah", Jurnal Pendidikan Islam, Vol.1 No. 2 (Desember 2012),

Munip, Abdul, (2012) "Menangkal radikalisme Agama di Sekolah" Jurnal Pendidikan Islam, Vol.1, No.2, (Desember 2012)

Naim, Ngainun (2008), Pendidikan Multikultural, Konsep dan Aplikasi Yogyakarta: ArRuzz Media Group,

Ramayulis. (2011) Ilmu Pendidikan Islam, Jakarta, Kalam Mulia, Cet. IX,

Roqib, Moh (2009), Ilmu Pendidikan Islam Pengembangan pendidikan Integratif di Sekolah Keluarga dan Masyarakat, Yogyakarta;LKis,

Shaleh, Rahman, Abdul, (2006), Pendidikan Agama dan Pembangunan Watak Bangsa, Jakarta: PT Raja Grafindo Persada,

Sumartana, (2001) Pluralisme Konflik dan Pendidikan Agama di Indonesia Yoyakarta Interfidei

Syam, Nur, (2009), Tantangan Multiklturalisme Indonesia dari Radikalisme Menuju Kebangsaan, Yogyakarta: Kansius,

Tayibi, Imam, dkk, (2003) "Radikalisme Agama Sebagai Salah Satu Bentuk Perilaku Menyimpang” Jurnal Kriminologi Indonesia, Vol.3 No.1 (Juni:2003), 
Thoha, Chabib, (1996) Kapita Selekta Pendidikan Islam, Yogyakarta: Pustaka Pelajar, Cet. 1 ,

Zuhairini, dkk., (1993), Metodologi Pendidikan Agama, Solo: Ramadhani, Cet.I, 